\title{
MASS BALANCE APPROACH FOR ESTIMATING VOLATILE ORGANIC COMPOUNDS EMISSIONS FROM AUTOMOTIVE INDUSTRY
}

\author{
Darlan Pereira ${ }^{l}$ \\ Sérgio Correa ${ }^{2}$ \\ Eduardo B. de Azevedo \\ ${ }^{\prime}$ University of Kalmar, Sweden \\ 'State University of Rio de Janeiro, Brazil \\ ${ }^{3}$ University of Sao Paulo-USP, Brazil
}

\begin{abstract}
During the last several decades, the automotive coating industry has faced air pollution control problems arising from their daily operations. Emissions from surface coating operations include volatile organic compounds (VOCs), several inorganic pollutants and particulate matter. The limit of VOCs emissions established by the European Union for automotive coating industry is $60 \mathrm{~g} / \mathrm{m}^{2}$. No threshold limits are established in Brazil for this particular industrial branch. Using the material balance approach, an estimate of the VOCs from automotive surface coating operations that uses solvent-base and water-base coatings was performed. Based on consumption and composition of raw materials; area of painted surfaces; and amount of emissions captured in vapor and liquid phases; it was possible to estimate the VOCs concentrations emitted by unit of painted surface area. The accuracy of this mass balance approach was estimated by comparing results from lab tests of VOC samples collected in three different emissions points before treatment.
\end{abstract}

\section{KEYWORDS}

Automotive coating; Air emissions; Material balance; VOCs.

\section{INTRODUCTION}

Volatile Organic Compounds (VOCs) are emitted from different types of sources. Surface coating operations, such as painting, are common sources of VOCs emissions. The amounts and types of VOCs emitted from any process depend greatly on the type of paint, process and the configuration and rate of air flow through the paint booth and dry oven. Some VOCs are health hazards and many of them contribute to the atmospheric pollution through complex chemical reactions in the atmosphere that may cause a number of indirect effects, in particular the formation of photochemical oxidants (smog forming) and their main constituent, ozone. Automotive coating raises relevant environmental issues such as VOCs emissions, global warming and waste generation. Coatings consist of solids (e.g. resin, pigments, extenders, additives) and solvents. The air emissions come from the evaporation of organic solvents. They consist primarily of VOCs, such as toluene, xylene, ethyl acetate, and n-butyl acetate [1] 
and can occur in a number of places along the production line: during application of the coating (overspray), during initial air drying of the vehicle body after they leave the spray booth, and in the dry oven (curing process). Fugitive emissions are sometimes difficult to capture when the process has auxiliary equipment considerations, human inspection requirements or frequent cleaning procedures to follow.

A variant of the alternative method provided in the Emission Inventory Improvement Program (EIIP) document was used to develop estimative of VOCs emissions from surface coating operations, as material balance approach. The choice of methods [2] to be used to estimate emissions depends on how the estimates will be used and the degree of accuracy required.

Material balance utilizes the raw material usage rate to estimate the amount of pollutant emitted. Other information relating to material usage, such as fraction of the pollutant in the raw material and the amount of material recycled, disposed, or converted to another form, is also included in a material balance calculation [3].

The limit of VOC emissions established according the European Union Directive 1999/13/EC for automotive coating industry is $60 \mathrm{~g} / \mathrm{m}^{2}$ for existing installations and $45 \mathrm{~g} / \mathrm{m}^{2}$ for new installations that produces more than 5,000 vehicles per year. No threshold limits are established in Brazil for this particular industrial branch.

This paper presents the result of an investigation carried out at one automotive manufacturer in Rio de Janeiro State, Brazil, that produces four different types of passenger vehicles. The total consumption of paint used in surface coating by this industry is about $72 \mathrm{ton} / \mathrm{month}$. The production is around 5,000 vehicles per month and the operation time is 16 hours per day and 22 days. Three thermal incinerators are used to control and reduce the VOCs emissions.

The estimative of VOCs emissions using a mass balance approach have been compared with the results from lab tests of VOC samples collected in three different emissions points before treatment during a normal month of production.

\subsection{Manufacturing processes characterization}

In general, several layers of coating are necessary in vehicle coating processes. The traditional painting process includes solvent-based primer + base coat + clear coat (lacquer), which is featured by its high quality and easy application, however, large VOCs emission exists.

The process studied (Figure 1) include: (1) pre-treatment; (2) electrodeposition coat or cataphorese; (3) cataphorese dry oven, (4) PVC water-proof, sound-proof painting and stoneproof spray booth; (5) primer/guide spray booth; (6) primer coat dry oven; (7) base coat and lacquer spray booth; (8) base coat and lacquer dry oven. There is also a finishing area, connected to the main process, used to make repairs in the vehicle body after primer coat or base coat and lacquer dry oven, if necessary. In this area two spray booths and two dry ovens are used, their capacity is only one vehicle per repair. 


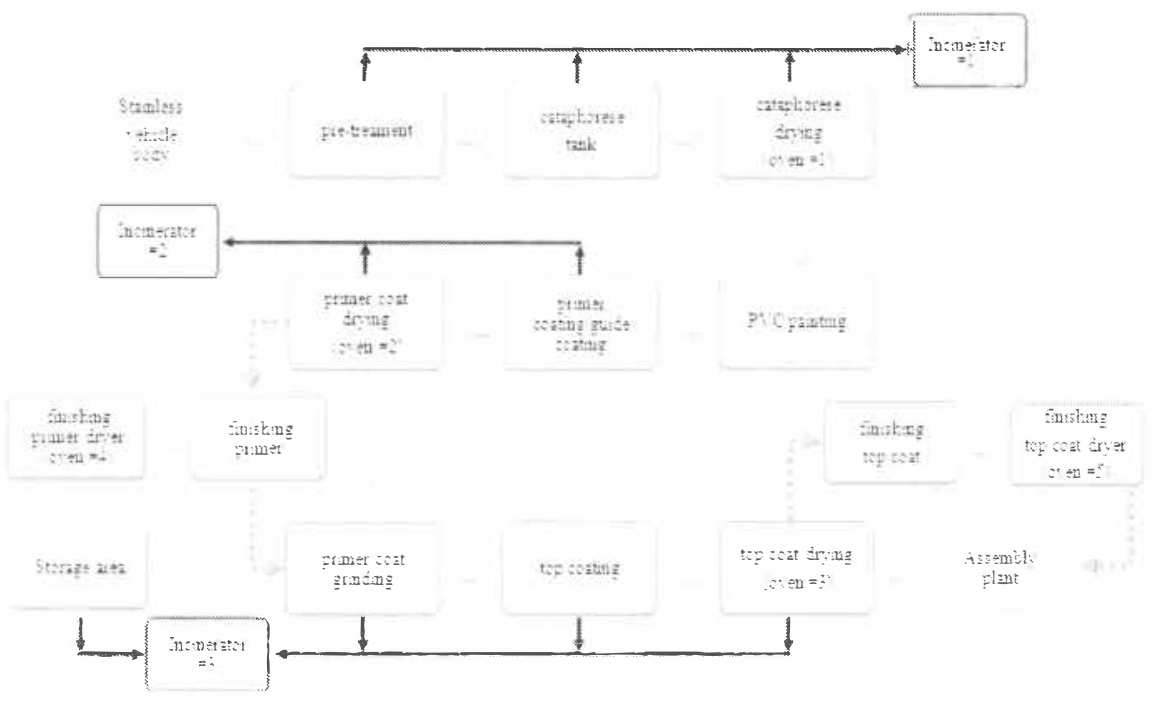

Figure 1: Painting process and ventilation system from the automotive coating.

The steel vehicle bodies are initially pre-treated with a cleanup agent (an alkaline cleaning solution), hot bath drying, degreasing and surface adjustment. The most important step in this process is a phosphate treatment which is used to improve corrosion resistance and prepares metal surfaces for the electrodeposition coating.

Electrodeposition is the process for which the paint and the vehicle carry opposite electrical charges in order to deposit a paint film on the vehicle body. The painting is applied by dipping the vehicle body into an electrostatic fluidized tank. In this tank, the painting particles are attracted to grounded vehicle body moving through the tank.

The PVC spraying is applied to protect specials parts and areas of the vehicle body from water, sound-proof painting and stone-proof painting. This process is manually: a specific pistol is used in a spray booth where the air flow rate and humidity are controlled.

Primer is any coating applied prior to the application of a base coat for the purpose of corrosion resistance, adhesion of the base coat and color uniformity. Without adequate primer adhesion to the surface the subsequent coatings may not adhere properly. In addition, primers serve to prevent corrosion in one of three ways: physically, as a barrier; chemically, with the use of corrosion-inhibiting agents; or electrochemically.

The base coat (solid coating or metallic coating) and lacquer (transparent clear coat) are the final film of coating. They are applied in the same spray booth after the surface has been prepared and free of defects. Base coat and lacquer provides additional resistance to the 
environment and help to protect the primer and intermediate coats from exposure to weather and chemicals. They also provide the final color and appearance.

Inside of the spray booth primer, base coat and lacquer, temperature and humidity are controlled, around $18.0 \pm 2^{\circ} \mathrm{C}$ and $0.7 \pm 0.1$, respectively. There is also filtered air coming from the roof to send the overspray over to the grating floor to captured VOCs in vapor phase by the ventilation and in liquid phase by a water system (see Figure 2).

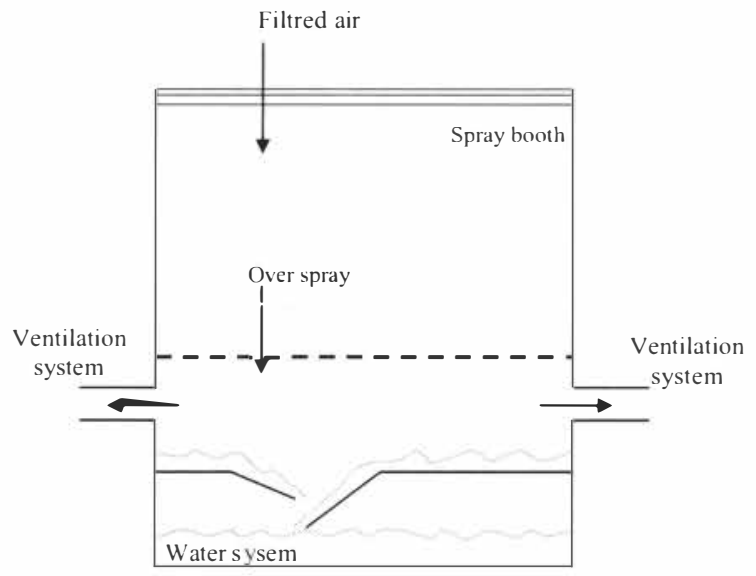

Figure 2: Primer, base coat and lacquer spray booth system.

In the automotive industry, it is a common practice to correct small surface imperfections, such as those arising from dust or dirt particles and scratches, by sanding and polishing. If imperfections remain on the surface after primer or base coat and lacquer dry ovens, the vehicle body can be transferred to an auxiliary line (finishing paint area) to be repaired and returned to the main process. The finishing paint area includes two spray booths for primer or base coat and lacquer and two smaller dry ovens. According to the industry, the finishing area is used for $2 \%$ or less of the vehicle bodies painted.

A storage area is used to keep the painting containers in temperature and humidity controlled. The containers are opened in this area and placed in the painting distribution system to the primer, base coat and lacquer spray booth.

A ventilation system capture the air coming out from ten different areas to be treated: (1) paint storage area; (2) pre-treatment; (3) cataphorese; (4) cataphorese dry oven; (5) primer spray booth; (6) primer dry oven; (7) base coat and lacquer spray booth; (8) base coat and lacquer dry oven; (9) finishing ovens; and, (10) after drying areas. They are connected to three main ventilations systems that send the air collected to incineration.

The heating system, Figure 3, is used to keep hot air coming into the drying oven. This system takes air from the different areas inside of the automotive coating and changes heat with the air coming out from the incinerator system. 


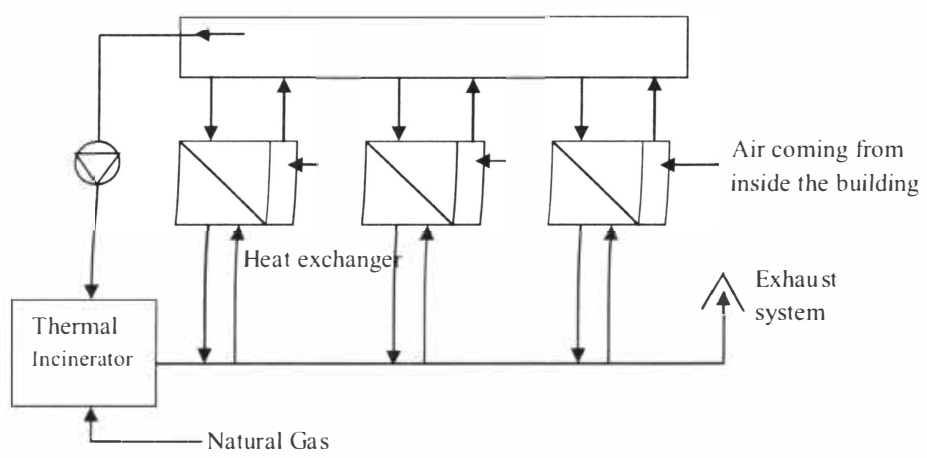

Figure 3: Heating and air treatment system.

\section{MATERIALS AND METHODS}

\subsection{Emission Points}

The majority of emissions occur during surface coating and curing process inside the dry ovens. The emissions points to be considered are: (1) pre-treatment; (2) cataphorese; (3) cataphorese dry oven, (4) PVC water-proof, sound-proof painting and stone-proof spray booth; (5) primer spray booth; (6) primer dry oven; (7) base coat and lacquer spray booth; and, (9) base coat and lacquer dry oven.

\subsection{Estimation of VOCs Emissions}

This study applies a material balance approach to estimate VOCs emissions from an automotive painting plant. The percentage of VOCs solvent in the coating, given in the Material Safety Data Sheet (MSDS), multiplied by the quantity of coating used yields the total emissions from the coating. Solvents used for cleaning are also inputs in the process. The mass of solvent captured in vapor phase was given by air samples collected before treatment and analyzed in lab. The overall VOCs emission, of each emission point was illustrated as Equation 1.

$V^{\prime} E=\frac{\left[\left(V C_{n} \cdot V O C_{n}\right)+S o l v_{n}-\left(R S_{4}+R S_{B}\right)\right]}{B \cdot S} * 1000$

where VE is grams of VOC per area painted $\left(\mathrm{g} / \mathrm{m}^{2}\right) ; \mathrm{VC}_{\mathrm{n}}$, volume of raw material per month

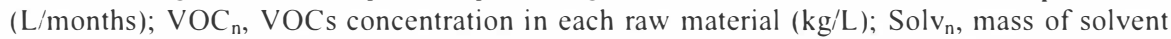
used per month ( $\mathrm{kg} /$ month); $\mathrm{RS}_{\mathrm{A}}$, mass of solvent captured in vapor phase $(\mathrm{kg} / \mathrm{month}) ; \mathrm{RS}_{\mathrm{B}}$. mass of solvent captured in liquid phase $(\mathrm{kg} /$ month); $\mathrm{B}$, vehicle bodies painted per month (vehicle/month); and $\mathrm{S}$, vehicle body area painted $\left(\mathrm{m}^{2}\right.$ vehicle).

Air samples from: cataphorese, primer, base coat and lacquer ventilation system, before the thermal incinerator were collected. For each point, four samples were collected using the VOST equipment (Volatile Organic Sampling Train). These samples were analyzed by Purge and Trap GC/MS volatile organic analyses (P/T GC/MS VOAs) to determinate VOC emissions in the flue gases. (METHOD 8260C, EPA, 2006). 
According to Table 1 the production in the month that has been studied is 5,190 vehicles, divided in four different models. The respective area (surface of the electrophoretic coating) is also given.

Table 1: Production and surface painted.

\begin{tabular}{ccc}
\hline Veihcle body & $\begin{array}{c}\text { Production } \\
\left(\text { veihcle } \text { month }^{-1}\right)\end{array}$ & $\begin{array}{c}\text { Surface painted } \\
\left(\mathrm{m}^{2}\right)\end{array}$ \\
\hline Model 1 & 2,470 & 75.6 \\
Model 2 & 870 & 83.9 \\
Model 3 & 1,050 & 91.1 \\
Model 4 & 800 & 80.8 \\
\hline
\end{tabular}

\section{RESULTS AND DISCUSSION}

The organic solvents used in the coating and for cleaning process include: butyl glycol, 2butoxyethanol, acetic acid, hexane, n-butyl alcohol, isobutyl alcohol 2-butoxyethanol acetate, 2-butanone, formaldehyde, isopropyl alcohol, n-propyl alcohol, n-butyl acetate, xylene, ethyl benzene, ethylene oxide, 1,2,4-trimethylbenzene, ethyl alcohol, sec-butyl alcohol, dipropylene glycol methyl ether and propylene glycol monomethyl ether.

Table 2 summarizes the consumption of solvents in each spray booth. According to Table 1, the amount of solvents used for cleaning process represents $43 \%$ of the total solvents used.

Emissions characteristics in the selected areas were estimated and summarized, as follows:

(1) Pre-treatment: no concentrations of VOCs compounds were found in the products applied in this step. The air emissions are characterized by $\mathrm{CO}, \mathrm{CO}_{2}, \mathrm{NO}, \mathrm{NO}_{2}, \mathrm{Cr}, \mathrm{HF}$, alkalinity $\left(\mathrm{OH}^{-}\right)$and acidity $\left(\mathrm{H}_{3} \mathrm{O}^{+}\right)$, according to analysis from the exhaust system.

(2) Cataphorese: the air emission from cataphorese tank is captured by the same ventilation system that captures the air from the dry oven. The cataphorese has high percentage the solids in the paint, however, is necessary to use solvents for dilutions process. There is a spray water system (deionized and demineralized water) after the electrodeposition coating to wash the vehicle body and remove the excess, which is filtered and re-circulated to the tank.

(4) PVC water-proof, sound-proof painting and stone-proof spray booth: these painting products contain extremely low VOCs concentrations in theirs composition and, therefore, the emissions can be neglected.

(5) Primer, base coat and lacquer: the overspray is captured in vapor and liquid phase by ventilation and water system under the spray booth floor (see Figure 3) during primer application, same as base coat and lacquer.

In the primer spray booth $4 \%$ and $9 \%$ of the solvents used is captured in liquid and vapor phase respectively, whereas in the base coat and lacquer spray booth the percentage is lower, $3 \%$ and $7 \%$, respectively. The lacquer is applied by electrostatic spraying; therefore, the percentage of overspray is lower than primer and base coat. However, the percentage of solvents in lacquer paint $(7.1 \%)$ is high than primer $(1.9 \%)$ and base coat $(5.9 \%)$. 
Other source of air emissions from the spray booth (e.g. opening doors, maintenance) are captured by the main ventilation system and followed to incineration. Some primers applied are water-based and contain little or no organic solvent.

(6) Drying ovens: data from the curing process as temperature and air flow were characterized (see Table 3). The air emissions captured in the dry ovens are mixed with the air emissions captured from the spray booth during the incineration process, which occurs at $550 \pm 50^{\circ} \mathrm{C}$ in each incinerator. The curing time is similar for cataphorese, primer, base coat and lacquer, around 1.5 hours.

(7) Finishing area and storage painting area: the consumption of solvent used in the finishing area is less than $0.5 \%$ of the main process. The containers used in the storage area are airtight and the maintenance proceedings occur very rarely. Therefore, the emissions from these areas can be also neglected.

Table 2: VOC emissions.

\begin{tabular}{lcccc}
\hline $\begin{array}{l}\text { Emissions points } \\
\text { (dry ovens) }\end{array}$ & $\begin{array}{c}\text { Solvent } \\
\text { consumption } \\
(\mathrm{kg} / \text { month })\end{array}$ & $\begin{array}{c}\text { Solvent captured } \\
\text { in liquid phase } \\
(\mathrm{kg} / \text { month })\end{array}$ & $\begin{array}{c}\text { Solvent captured } \\
\text { in vapor phase } \\
(\mathrm{kg} / \mathrm{month})\end{array}$ & $\begin{array}{c}\mathrm{VE} \\
\left(\mathrm{g} / \mathrm{m}^{2}\right)\end{array}$ \\
\hline Cataphorese & 2,746 & - & 205 & 6.05 \\
Primer & 3,459 & 71 & 143 & 3.44 \\
Base coat and Lacquer & 9,462 & 224 & 592 & 18.21 \\
\hline
\end{tabular}

Table 3: Comparison between data of measurement and estimates.

\begin{tabular}{lccccc}
\hline $\begin{array}{l}\text { Emissions } \\
\text { points } \\
\text { (dry ovens) }\end{array}$ & $\begin{array}{c}\text { Flow rate } \\
\left(\mathrm{m}^{3} / \mathrm{h}\right)\end{array}$ & $\begin{array}{c}\text { Temperature } \\
\left({ }^{\circ} \mathrm{C}\right)\end{array}$ & $\begin{array}{c}\mathrm{C}_{\text {COV }} \\
\text { measured } \\
\left(\mathrm{g} / \mathrm{m}^{3}\right)\end{array}$ & $\begin{array}{c}\mathrm{C}_{\text {COV }} \\
\text { estimated } \\
\left(\mathrm{g} / \mathrm{m}^{3}\right)\end{array}$ & $\begin{array}{c}\text { Measured/ } \\
\text { estimated }(\%)\end{array}$ \\
\hline $\begin{array}{l}\text { Cataforese } \\
\text { Primer }\end{array}$ & 10,000 & $190 \pm 15$ & 8.47 & 12.31 & 70 \\
$\begin{array}{l}\text { Base coar and } \\
\text { Lacquer }\end{array}$ & 18,100 & $165 \pm 15$ & 0.29 & 0.38 & 77 \\
\hline
\end{tabular}

Top coat (base coat and lacquer) are the main source for VOC emission in this automotive coating surface process, which releases $18.21 \mathrm{~g} / \mathrm{m}^{2}$ of the total VOCs emissions of 27.70 $\mathrm{g} / \mathrm{m}^{2}$. Most of the developed countries have specified the VOC emission regulation to improve the environment protection, such as $60 \mathrm{~g} / \mathrm{m}^{2}$ in Europe.

As seen in Table 3, the emissions from a primer water-base coating are 5 times lower than solvent-base (base coat and lacquer). Solvent based for metallic base coat is the major source for VOC emission, accounting for $10 \%$ of solvent in the paint composition applied.

In order to comply issued regulations, many paint manufacturers are developing waterborne coatings systems for automobile coating industry [4]. 
Comparing the estimated data by material balance approach and measured tests in laboratories, the degree of accuracy is satisfactory for daily estimative of VOCs emissions.

\section{CONCLUSIONS}

The result shows that the material balance approach can be applied in automotives surface coating once the degree of accuracy required is not high. This methodology could be applied in tests for reduction of emissions when the composition of raw materials is changing or for prediction of air emissions by increasing of production. This method of emissions estimation avoids the requirement to use variables such as transfer efficiency, which are often difficult to define precisely; however, it is not efficiency for a large percentage of fugitive gas emissions.

Testing (sampling and analyses) is typically the most preferred source of emissions data from a specific source, although they are very expensive and unviable to be applied in medium and small size automotive coating in Brazil.

Introduction of water born painting, which is effective in reduction of VOC emission, will be accelerated in automotive coating lines due to the improvement of paint, application technology and restriction of VOC emissions. Although the low solvent content coatings can reduce the VOCs emissions, working with this kind of paints is more difficult. The waterborne coatings have been widely used in Europe and North America.

\section{REFERENCES}

[1] EIIP, 2001. Technical Report Series. Chapter 7 in EIIP Volume II. Point Sources Preferred and Alternative Methods for Estimating Air Emissions from Surface Coating Operations. U.S. Environmental Protection Agency, Office of Air Quality Planning and Standards, 51-64

[2] Dewulf, T. A., Wherrett, M. R., 2003. Comparison of measurement methodology on volatile organic compounds emitted from automotive surface coating operations. Dearborn, Michigan: Ford Motor Company - Environmental Quality Office, 19-33.

[3] Chang, C-T., Jeng, F-T., 1998. Study on the strategies of waste solvent minimization in automobile production industry. Proceedings of the $91^{s t}$ Annual Meeting and Exhibition of Air and Waste Management Association, June 14-18, San Diego, California, USA (1998).

[4] Geldernann, J. et al, 2007. An integrated scenario analysis for the metal coating sector in Europe. Technol. Forecast. Soc. Change 74, 1482-1507. 